DOI 10.37882/2223-2982.2021.03.21

\title{
ФОНЕТИЧЕСКАЯ РЕАЛИЗАЦИЯ ИК-2 В ЭТАЛОННЫХ ПРОИЗНЕСЕНИЯХ НА РУССКОМ ЯЗЫКЕ В ВОПРОСИТЕЛЬНЫХ ПРЕДЛОЖЕНИЯХ
}

\section{PHONETIC REALIZATION OF INTONATIONAL CONSTRUCTIONS №2 IN REFERENCE PRONUNCIATION IN RUSSIAN INTERROGATIVE SENTENCES}

Li Luokai

Summary: This study, based on the experimental analysis of the pitch frequency on different parts of utterance, is devoted to phonetic realization of intonational construction (IC) №2 in reference pronunciation in Russian questions. During the experiment, by using Praat program were analyzed 50 sentences with pre-centers of IC №2, which were selected from audio accessories of modern works on teaching Russian as a foreign language. The obtained data show that phonetic realization of IC №2 depends on the type of sentence, which is classified by the pur-pose of utterance: the probability that pitch frequency falls at the stressed vowel of the accented word in one-syntagmatic interrogative sentences higher than in declaratives.

Keywords: phonetic, intonational construction, pitch frequency, timing.
И нтонация как важное средство формирования высказывания, в том числе, его смысла, является неотъемлемой частью устной речи. В лингвистике изучение интонации направлено на два аспекта: вопервых, в фонематическом аспекте языка интонация характеризуется как обозначаемая сторона непосредственно связана с семантико-синтаксической стороной предложения-высказывания; во-вторых, в фонетическом аспекте интонация характеризуется в качестве обозначающего, и напрямую имеет отношение к материальной стороне высказывания.

По мнению Н.В. Черемисиной, «интонация содержательна уже сама по себе, в «бессловесном», «произносимом» с закрытым ртом тексте; такая вневербальная интонация способна различать коммуникативные типы высказывания (утверждение, вопрос, побуждение), выражать эмоциональные значения и оттенки, сопутствующие «логической» или «волевой» интонации» [Черемисина, 1982: 23-24]. С точки зрения И.Г. Торсуевой, интонация в качестве единицы языка должна выполнять определенные функции, и ее функции являются одной из важнейших проблем для исследования интонации [Торсуева, 1968: 116].

Ф. Данеш, который считается основателем функци-

\author{
Ли Локай \\ Аспирант, Московский государственный университет \\ имени М.В. Ломоносова \\ loveangelgirl58@gmail.com
}

Аннотация: Данное экспериментальное исследование, выполненное на основе анализа частоты основного тона (ЧОТ) на разных частях высказывания, посвящено фонетической реализации ИК-2 в эталонных произнесениях на русском языке в вопросительных предложениях. В ходе эксперимента с помощью программы Praat были проанализированы 50 предложений с предцентровой частью, отобранные из аудиоприложениий к современным работам по преподаванию русского языка как иностранного. Полученные данные свидетельствуют о том, что фонетическая реализация ИК-2 может зависеть от типа предложения по цели высказывания: вероятность падения ЧОТ на ударном гласном в односинтагменных вопросительных предложениях выше, чем в повествовательных предложениях.

Ключевые слова: фонетика, интонационная конструкция, частота основного тона, падения, тайминг.

онального подхода к интонации, отмечал, что необходимо изучать функциональный аспект интонации; он попытался дать перечень её функций - разделяя их на первичные и вторичные (модальные) [Данеш, 1960: 34-54]. К первичным он относил способность интонации превращать слова в высказывания и выделять тему и рему высказывания; вторичные функции интонации, по мнению Ф. Данеша, соотносятся с возможностью интонации разграничивать высказывания по их цели и передавать эмоциональное содержание звучащей речи [Данеш, 1960: 48].

В связи со вторым аспектом в работе «Экспериментальная фонетика» В.А. Артемов отмечал, что «звуки речи с физической стороны характеризуются: 1) числом колебаний основного (голосового) тона, 2) обертонами (гармониками), 3) амплитудой (силой, интенсивностью) этих колебаний и 4) временем. Самые разнообразные сочетания этих элементов и образуют физическую основу звуков речи. Как показали наши исследования, физическая природа интонации та же самая. С физической точки зрения интонация представляет собой единое звуковое явление, состоящее из изменяющихся (расчленяющихся) во времени и взаимосвязанных: числа колебаний основного тона (числа герц), обертонов (гар- 
моник) и амплитуд интенсивности, иначе говоря, силы колебаний» [Артемов 1956: 35].

Интонационной конструкцией (ИК) в концепции Е.А. Брызгуновой называется тип соотношения тона, тембра, интенсивности и длительности звучащей речи, способный противопоставить несовместимые в одном контексте смысловые различия высказываний с одинаковым синтаксическим строением, но одинаковым звуковым составом словоформ. В русском языке выделяются семь типов ИК, фонетические различия которых связаны преимущественно с уровнями и направлением движения тона [Брызгунова, 1980: 96-97].

Фонетическая реализация ИК-2 также описана Е.А. Брызгуновой: «В реализациях ИК-2, близким к нейтральным, широко варьируется уровень тона, длительность и интенсивность гласного центра. Наиболее употребительные реализации ИК-2 имеют следующие особенности:

1. контур ИК-2 близок к контуру ИК-1, отличаясь от ИК-1, на гласном центра ИК-2 в более высоком уровне тона и усилении словесного ударения [Брызгунова, 1977: 26];

2. высокий уровень тона начинается на ударном слоге первого или одного из первых слов и держится до слога, выделенного центром ИК-2;

3. возможны реализации ИК-2, в которых гласный центра характеризуется увеличением длительности и восходяще-нисходящим движением тона» [Брызгунова, 1977:197-198].

В работе [Ли Локай, 2020] было проведено сопоставление фонетической реализации ИК-1 и ИК-2 в современном русском языке в односинтагменнных повествовательных предложениях методом анализа частоты основного тона (ЧОТ) на разных частях высказывания; в настоящей статье излагаются результаты экспериментального исследования фонетической реализации ИК-2 в односинтагменных вопросительных предложениях с помощью того же метода исследования.

Для эксперимента было отобрано 50 предложений с предцентровой частью из аудиозаписей к современным работам по преподаванию русского языка как иностранного [Одинцова, 2014: 134-136], [Бархударова, Панков, 2019: 9-10], записанных от 2 мужчин и 2 женщин: М1 и ж1 [Одинцова, 2014], М2 и Ж2 [Бархударова, Панков, 2019: 9-10].

В ходе эксперимента с помощью программы Praat были получены спектрограммы и интонограммы соответствующих записей и измерены следующие параметры:

- значение начального тона в синтагме с ИК-2;

- значение частоты основного тона (ЧОТ) в начале и конце падения;

- интервал падения;

- место падения;
- время начала падения относительно начала ударного гласного акцентированного слова.

Ниже на рис. 1 в качестве иллюстрации приведен пример измерений во фразе Где Ди²ма?.

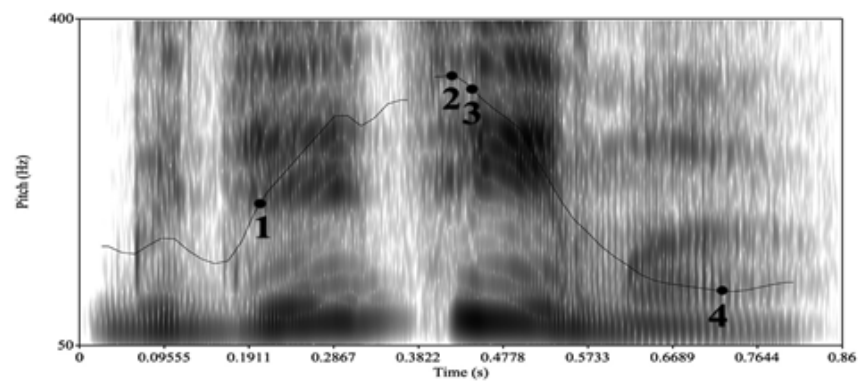

Рис. 1. Спектрограмма фразы, Где Ди2ма?

На рисунке 1 точки соответствуют следующим значениям:

- точка 1 - значение начального тона в синтагме, в данном случае 194.4 Гц;

- точка 2 - значение чОТ в начале падения, в данном случае 340 Гц;

- точка 3 - начало ударного гласного акцентированного слова

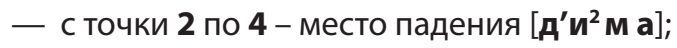

- точка 4 - значение чОТ в конце падения, 108 Гц, следовательно, интервал падения в данном случае равен 232 Гц.

- с точки 3 по 4 - время начала падения относительно начала ударного гласного акцентированного слова, - 015 мс.

Результаты измерений приведены в таблицах 1 и 2. В них представлены следующие данные: значение начального тона в синтагме, значение чОТ в начале и конце падения, интервал падения, время начала падения относительно начала ударного гласного, место падения в аудиофайлах с ИК-2.

На основании данных, приведенных в таблице 1, можно заключить:

У диктора-мужчины М1 диапазон значения частоты начального тона в синтагме составляет 115 - 145 Гц, в среднем 126 Гц; значение тона в начале падения изменяется в диапазоне 150-185Гц, в среднем 170 Гц; значение тона в конце падения находится в пределах 60-125 Гц, в среднем 96 Гц; интервал падения - 40-105 Гц, в среднем 74 Гц.

У диктора-женщины Ж1 диапазон значения частоты начального тона в синтагме составляет 200-315 Гц, в среднем 243 Гц; значение тона в начале падения изменяется в диапазоне 230 -355 Гц, в среднем 287 Гц; значение тона в конце падения находится в пределах120-185 Гц, в среднем 153 Гц; интервал падения - 85-195 Гц, в среднем 133 Гц. 
Таблица 1.

Начальный тон в синтагме, значение чОТ в начале и конце падения, интервал падения, время начала падения относительно начала ударного гласного, место падения, в аудиофайлах с вопросительными предложениями,

оформленными ИК-2 из [Одинцова 2014]

\begin{tabular}{|c|c|c|c|c|c|c|}
\hline $\begin{array}{c}\text { Экспериментальная фраза (вы- } \\
\text { делен центр ИК), диктор }\end{array}$ & $\begin{array}{c}\text { Значение на- } \\
\text { чального тона в } \\
\text { синтагме } \\
\text { (Гц) }\end{array}$ & $\begin{array}{c}\text { Значение ч0Т в } \\
\text { начале падения } \\
\text { (Гц) }\end{array}$ & $\begin{array}{c}\text { Значение ЧОТ в } \\
\text { конце падения } \\
\text { (Гц) }\end{array}$ & $\begin{array}{c}\text { Интервал } \\
\text { падения } \\
\text { (Гц) }\end{array}$ & $\begin{array}{c}\text { Время } \\
\text { начала падения } \\
\text { относительно } \\
\text { начала ударного } \\
\text { гласного (мс) }\end{array}$ & Место падения \\
\hline Зачем тебе это надо? (M1) & 142.2 & 173 & 98 & 75 & 0 & [ем т'и б'e ] \\
\hline 0 чём он спрашивал? (M1) & 115.4 & 150 & 83 & 67 & +077 & [а ш ы в ъ л] \\
\hline Где Наташа вчера была? (М1) & 117.4 & 177 & 94 & 83 & +077 & [а ш а в ч'и ра а ] \\
\hline 0 чём она вас просила? (M1) & 115.5 & 160 & 86 & 74 & +045 & [аспра] \\
\hline 0 чём они разговаривали? (M1) & 119.7 & 181 & 90 & 91 & +046 & [арр'ь в в л'ь] \\
\hline $\begin{array}{l}0 \text { чём они разговаривали в гостях? } \\
\text { (M1) }\end{array}$ & 128.7 & 170 & 121 & 49 & +032 & {$[я \mathrm{x}]$} \\
\hline Где он был? (М1) & 124.3 & 162 & 61 & 101 & +031 & [ыл] \\
\hline Где он был? (М1) & 125.9 & 182 & 88 & 94 & +060 & [0 н 6 ыл] \\
\hline Когда? (М1) & 144.7 & 169 & 125 & 44 & -015 & [да] \\
\hline Куда вечером сестра ходила? (М1) & 128.9 & 179 & 116 & 63 & -015 & [да] \\
\hline Куда он? (Ж1) & 313.8 & 319 & 136 & 183 & +029 & [a $0 \mathrm{H}]$ \\
\hline Почему ты опоздал? (Ж1) & 249.5 & 342 & 184 & 158 & +062 & [уты ы] \\
\hline Откуда она приехала? (Ж1) & 202.9 & 354 & 175 & 179 & -106 & [кудъана] \\
\hline Куда вы ходили? (Ж1) & 225 & 2263 & 122 & 141 & +061 & [и л' ь ] \\
\hline Что с вами случилось? (Ж1) & 238.3 & 265 & 142 & 123 & +046 & [иль с'] \\
\hline Куда вы ходили? (Ж1) & 213.3 & 285 & 152 & 133 & +045 & [ыхад'и] \\
\hline С кем он разговаривал? (Ж1) & 283.3 & 279 & 178 & 101 & +031 & [онраз] \\
\hline Какой фильм? (Ж1) & 239.7 & 321 & 127 & 194 & +014 & [ојффил'ь] \\
\hline Как у тебя с работой? (Ж1) & 253.5 & 273 & 149 & 124 & +014 & [ясрабо0] \\
\hline Что ты делаешь завтра? (Ж1) & 271.2 & 260 & 155 & 105 & +030 & [елаьшь] \\
\hline Что ты делаешь завтра? (Ж1) & 284.6 & 294 & 158 & 136 & +045 & [ы д’ела] \\
\hline Что ты делаешь завтра? (Ж1) & 212.8 & 234 & 140 & 94 & +073 & [а в т т р] \\
\hline В какой?Ж1) & 230.3 & 263 & 178 & 85 & +045 & [0j] \\
\hline Кому? (Ж1) & 216.8 & 281 & 164 & 117 & +062 & [y] \\
\hline Когда? (Ж1) & 212.1 & 266 & 137 & 129 & +015 & [a] \\
\hline
\end{tabular}

Следует отметить, что абсолютная частота женского голоса на разных частях синтагмы в среднем выше мужского на 55-120 Гц.

Данные таблицы 1 дают также возможность сделать вывод о том, что понижение частоты основного тона (ЧОТ) начинается за -106 - +077 мс. (в среднем - +032мс.) относительно начала ударного гласного, в $12 \%$ всех случаев начало понижения зафиксировано на согласном перед ударным гласным акцентированного слога, и в $88 \%$ - на ударном гласном (в 5\% случаев - именно на начале ударного гласного акцентированного слова и в 95\% - после начала ударного гласного, в среднем через 43 мс). Таким образом, начало падения у дикторов из пособия [Одинцова 2014] постоянно приходится на ударный слог акцентированного слова.

Из приведенных в таблице 2 данных, видно, что: 
Таблица 2.

Начальный тон в синтагме, значение ЧОТ в начале и конце падения, интервал падения, время начала падения относительно начала ударного гласного, место падения, интервал начального тона относительно тона в начале падения

в аудиофайлах с ИК-2 из [Бархударова, Панков 2019]

\begin{tabular}{|c|c|c|c|c|c|c|}
\hline $\begin{array}{c}\text { Экспериментальная фраза (выделен центр } \\
\text { ИК), диктор }\end{array}$ & $\begin{array}{l}\text { Значение на- } \\
\text { чального тона в } \\
\text { синтагме } \\
\text { (Гц }\end{array}$ & $\begin{array}{c}\text { Значение } \\
\text { чОТ в начале } \\
\text { падения (Гц) }\end{array}$ & $\begin{array}{c}\text { Значение } \\
\text { ч0Т в конце } \\
\text { падения (Гц) }\end{array}$ & $\begin{array}{c}\text { Интервал } \\
\text { падения } \\
\text { (Гц) }\end{array}$ & $\begin{array}{c}\text { Время } \\
\text { начала падения } \\
\text { относительно } \\
\text { начала ударного } \\
\text { гласного (мс) }\end{array}$ & Место падения \\
\hline Какой? (M2) & 113.3 & 388 & 102 & 286 & +045 & [oj] \\
\hline Откуда? (М2) & 113.2 & 339 & 154 & 185 & +015 & [уда] \\
\hline Зачем? (M2) & 121.8 & 324 & 203 & 121 & 0 & [ем] \\
\hline Почем? (М2) & 129.4 & 170 & 93 & 77 & 0 & [ем] \\
\hline Кому? (М2) & 130.5 & 167 & 96 & 71 & -059 & [m y] \\
\hline 0 ком? (M2) & 121.9 & 387 & 96 & 291 & +030 & [ом] \\
\hline 0 чём? (М2) & 125.6 & 177 & 98 & 79 & 0 & [ём] \\
\hline Какая сегодня погода? (M2) & 156.7 & 221 & 150 & 71 & 0 & [aja] \\
\hline Какое сегодня число? (М2) & 165.6 & 226 & 103 & 123 & 0 & [о ь с с'ив в од] \\
\hline Что такое литературная критика? (M2) & 261.9 & 335 & 103 & 232 & +030 & [урнъь кр'и] \\
\hline Кем были написаны эти мемуары? (M2) & 133.5 & 197 & 97 & 100 & +044 & {$[\mathrm{ncb}]$} \\
\hline Кем были написаны эти мемуары? (М2) & 145.8 & 203 & 105 & 98 & +064 & [э T'b $\left.M^{\prime} b\right]$ \\
\hline Какую? (M2) & 150.2 & 154 & 100 & 54 & -149 & [а ку] \\
\hline Что такое синонимы? (М2) & 136.7 & 173 & 74 & 99 & -074 & [н о О н'ь' \\
\hline Что такое комедия? (М2) & 111.6 & 176 & 64 & 112 & -094 & [M'e] \\
\hline $\begin{array}{l}\text { Какие науки составляют } \\
\text { филологию? (Ж2) }\end{array}$ & 276.7 & 343 & 198 & 145 & +060 & [иьннау] \\
\hline В каком месяце родился Блок? (Ж2) & 245.5 & 335 & 209 & 126 & +075 & [о м м'e] \\
\hline Кто говорит? (Ж2) & 278.1 & 318 & 150 & 168 & -110 & [а р'и] \\
\hline Откуда? (Ж2) & 239 & 318 & 154 & 164 & -015 & [куд] \\
\hline Что вам надо? (Ж2) & 234.4 & 330 & 160 & 170 & -076 & [мнадъ] \\
\hline Для кого? (Ж2) & 177.4 & 325 & 71 & 254 & -123 & [а в 0 0] \\
\hline Что ты вчера читал? (Ж2) & 256.5 & 346 & 148 & 198 & -165 & [итал] \\
\hline Какой это был день? (Ж2) & 261.3 & 363 & 151 & 212 & -015 & [којэть] \\
\hline Когда Пушкин написал стихотворение? (Ж2) & 306.2 & 362 & 175 & 187 & -015 & [дапу] \\
\hline $\begin{array}{l}\text { Кому посвящено стихотворение Пушкина? } \\
\text { (Ж2) }\end{array}$ & 231.9 & 311 & 156 & 155 & +016 & [у п ъ] \\
\hline
\end{tabular}

- У диктора-мужчины M2 диапазон значения частоты начального тона в синтагме составляет 110-265 Гц, в среднем 141 Гц; значение ЧОТ в начале падения изменяется в диапазоне 150-390 Гц, в среднем 242 Гц; значение чОТ в конце падения находится в пределах 60 -205 Гц, в среднем 109 Гц; интервал падения - 50-295 Гц, в среднем 133 Гц.
- У диктора-женщины Ж2 диапазон значения частоты начального тона в синтагме составляет 175-310 Гц, в среднем 251 Гц; значение чОТ в начале падения изменяется в диапазоне 310-365 Гц, в среднем 335 Гц; значение чОТ в конце падения находится в пределах 70-210 Гц, в среднем 157 Гц; интервал падения - 125-255 Гц, в среднем 178 Гц. 
Абсолютная значение ЧОТ женского голоса на разных частях синтагмы в среднем выше мужского на 45-110 Гц.

Данные таблицы 2 позволяют также утверждать, что понижение ЧОТ в речи дикторов исследованного пособия начинается за -165 - +075 мс. (в среднем - -021 мс.) до начала ударного гласного и в 4\% всех случаев начало понижения зафиксировано на предшествующем слове перед акцентированным словом, в 16\% случаев - на предударном слоге в акцентированном слове, в 24\% на согласном перед ударным гласным акцентированного слога; в 56\% случаев начало падения приходится на ударный гласный акцентированного слова (в $36 \%$ случаев - именно на начало ударного гласного акцентированного слова и в $64 \%$ - после начала ударного гласного, в среднем - через 27 мс после его начала). Таким образом, у дикторов из пособия [Бархударова, Панков 2019] начало падения приходится на ударный слог акцентированного слова в 80\% всех исследованных случаев.

Ниже на рисунках 2, 3, 4, 5 приведены обобщенные данные о месте начала падения ЧОТ во фразах с ИК-2 в односинтагменных вопросительных предложениях (по результатам настоящего исследования) и в односинтагменных повествовательных предложениях ([Ли Локай, 2020]).

Опираясь на данные, приведенные в таблицах 1, 2 и обобщенные на рисунках 2 - 5 можно заключить:

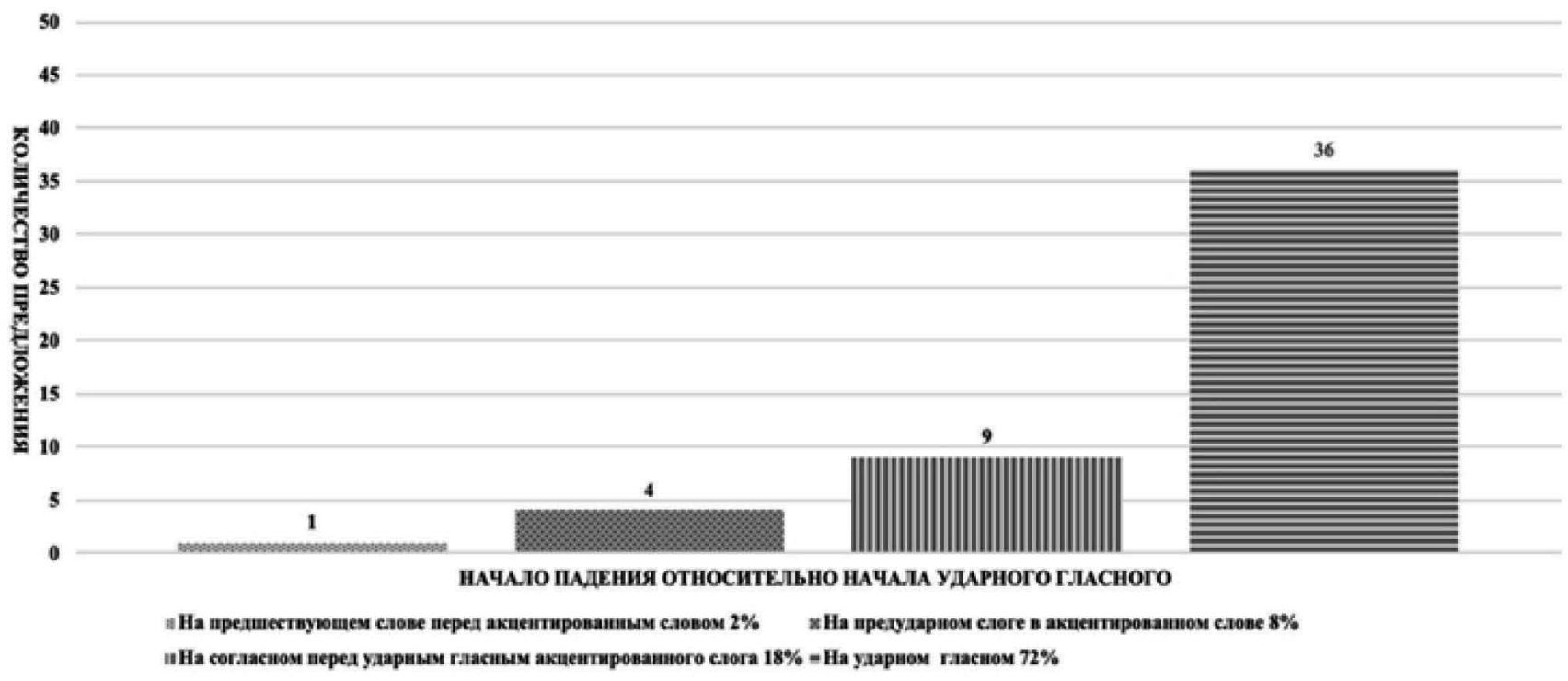

Рис. 2. Место начала падения ЧОТ во фразах с ИК-2 в односинтагменных вопросительных предложениях

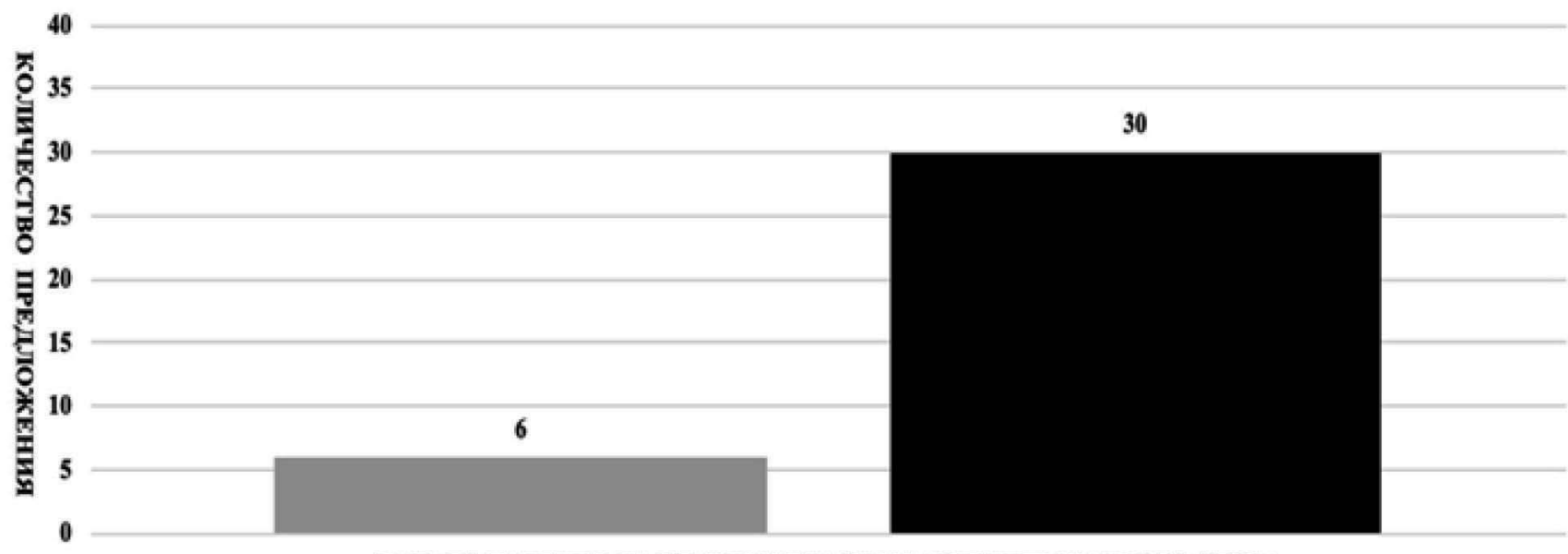

НАЧАЛО ПАДЕНИЯ НА УДАРНОМ ГЛАСНОМ АКЩЕНТИРОВАННОГО СЛОВА

- На начале ударного гласного акцентированного слова $17 \%$ пПоеле начала ударного гаaсного акцентированного слова $83 \%$

Рис. 3. Место начала падения ЧОТ на ударном гласном акцентированного слова во фразах с ИК-2 в односинтагменных вопросительных предложениях 


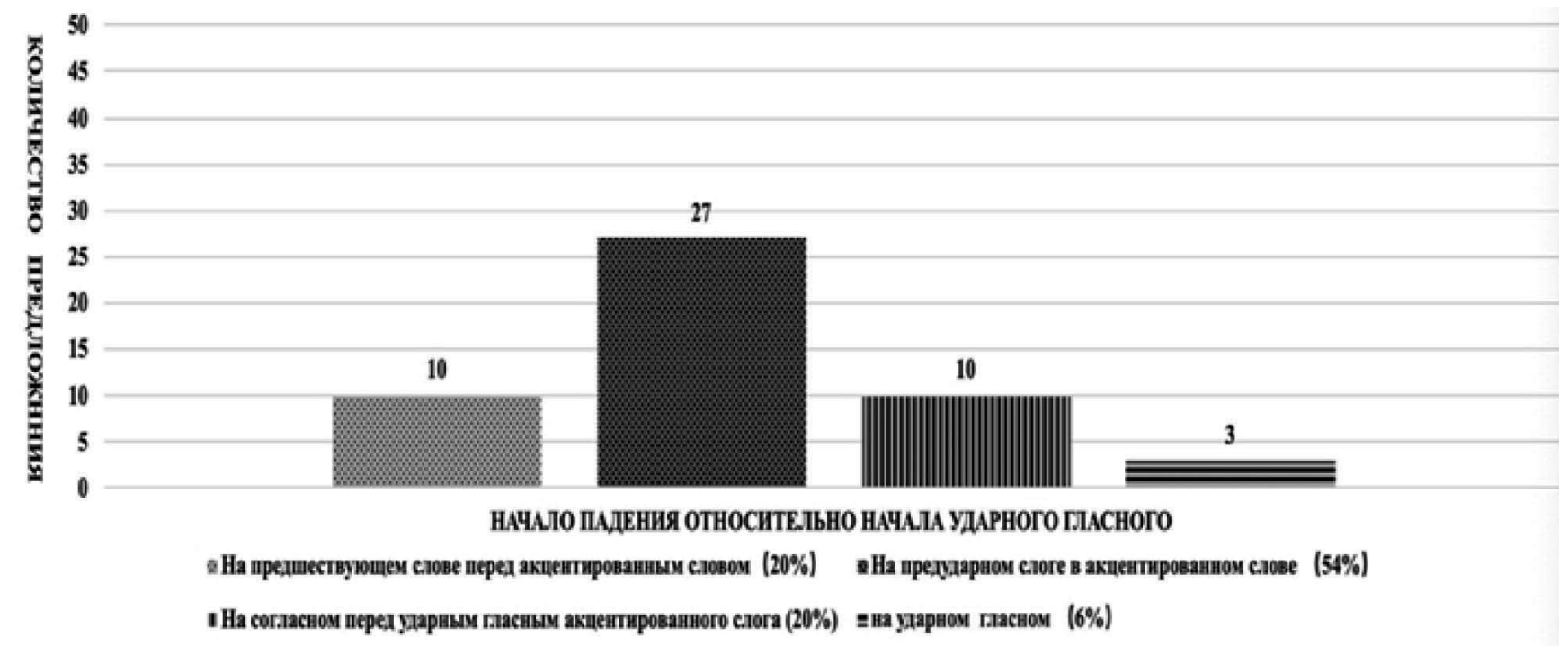

Рис. 4. Место начала падения чОТ во фразах с ИК-1

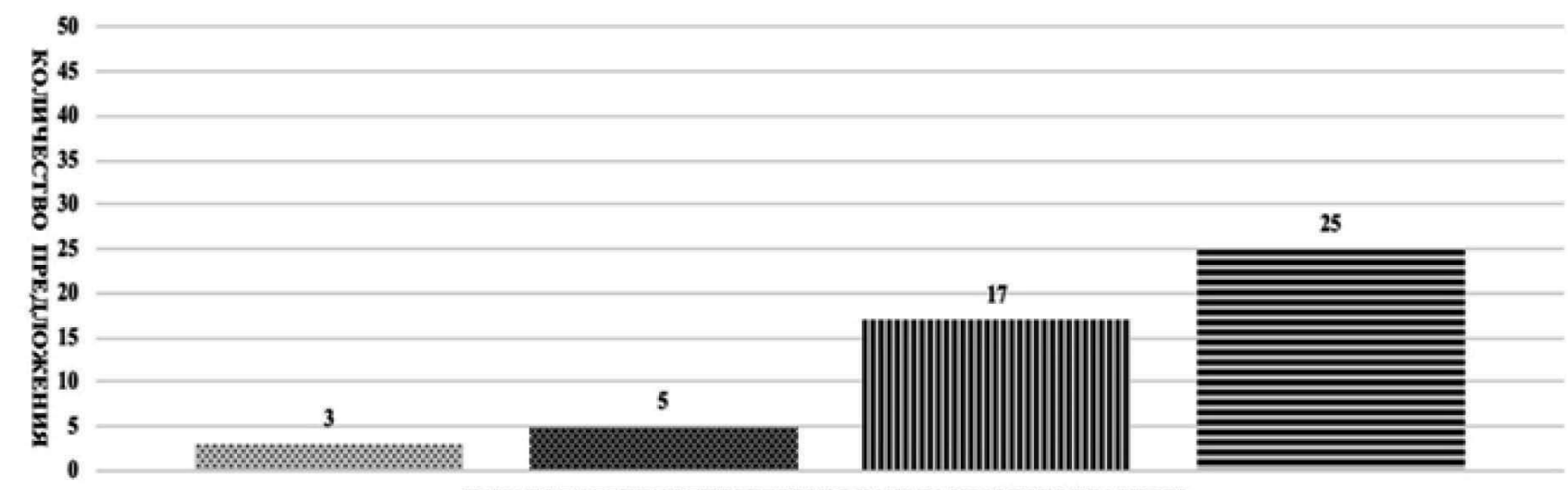

НАЧАЛО ПАДЕНИЯ ОТНОСИТЕЛЬНО НАЧАЛА УДАРНОГО Г.АСНОГО

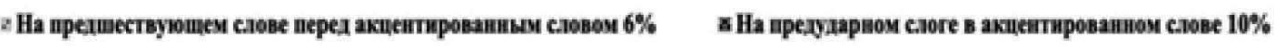

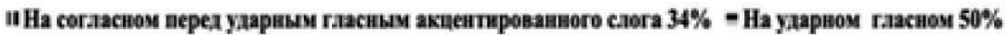

Рис. 5. Место начала падения ЧОТ во фразах с ИК-2

в односинтагменных повествовательных предложениях [Ли Локай, 2020]

Понижение ЧОТ в 50 исследованных эталонных вопросительных фразах, оформленных ИК-2, начинается за -165 - +077 мс., в среднем - +006 мс. относительно начала ударного гласного, при этом в $2 \%$ всех случаев начало понижения зафиксировано на слове, предшествующем акцентированному, в 8\% случаев - на предударном слоге в акцентированном слове, и в 18\% - на согласном перед ударным гласным акцентированного слога. Таким образом, падение тона в ИК-2 в односинтагменных вопросительных предложениях в 90\% всех исследованных случаев начиналось на ударном слоге акцентированного слова, в 72\% на ударном гласном акцентированного слова (из них - в 83\% - после начала ударного гласного акцентированного слова (в среднем - +037мс.).

В работе [Ли Локай, 2020] было установлено, что 1) в эталонных фразах, оформленных ИК-1, в односинтагменных повествовательных предложениях начало падения частоты основного тона в 94\% всех исследованных случаев начинается до начала ударного гласного акцентированного слова (за -376 - 0 мс., в среднем - -161 мс.), лишь в 6\% оно приходится на ударный гласный (см. рисунок 4) ; 2) в эталонных фразах, оформленных ИК-2, в односинтагменных повествовательных предложениях начало падения частоты основного тона начинается в диапазоне от -277 мс до + 106 мс. (в среднем - -065 мс.) относительно начала ударного гласного и приходится на ударный гласный акцентированного слова в 50\% случаев (см. рисунок 5), в то время как в эталонных фразах, оформленных ИК-2, в односинтагменных вопросительных предложениях, это происходит в 72\% случаев (отличия от ИК-2 в односинтагменных повествовательных предложениях 
составляют 22\%) - из этого следует, что фонетическая реализация ИК-2 может зависеть от типа предложения по цели высказывания: вероятность падения ЧОТ на ударном гласном в односинтагменных вопросительных предложениях выше, чем в повествовательных пред- ложениях. Причиной этого явления может служить тот факт, что вопросительные предложения не могут быть оформлены в СРЛЯ при помощи ИК-1, поэтому не существует необходимости отличать ИК-1 от ИК-2 за счет тайминга нисходящего акцента в высказываниях этого типа.

\section{ЛИТЕРАТУРА}

1. Артемов В.А. Экспериментальная фонетика. М., 1956.

2. Бархударова Е.Л., Панков Ф.И. По-русски - с хорошим произношением: Практический курс звучащей речи: учебное пособие для иностранных учащихся гуманитарных специальностей. М., 2019.

3. Брызгунова Е.А. Звуки и интонация русской речи. М., 1977.

4. Брызгунова Е.А. Интонация // Русская грамматика. М., 1980. Т.І. С. $96-122$.

5. Локай Ли. Фонетическая реализация тональных параметров в повествовательных предложениях, оформленных ИК-1 и ИК-2, в русском языке // вестник МГУ Серия 9. Филология. 2020. № 6. С.106-122.

6. Одинцова И.В. Звуки. Ритмика. Интонация: учеб. пособие. М., 2014.

7. Торсуева И.Г. Дискретный характер интонации и возможности ее типологического изучения// Уч. зап. 1 МГПИИЯ. М., 1968. Вып. 42. С. 116-122.

8. Черемисина Н.В. Русская Интонация. М., 1982.

9. Daneš F. Sentence intonation from a functional point of view // Word. 1960. Vol.16. №1. p.34-54. 2020.

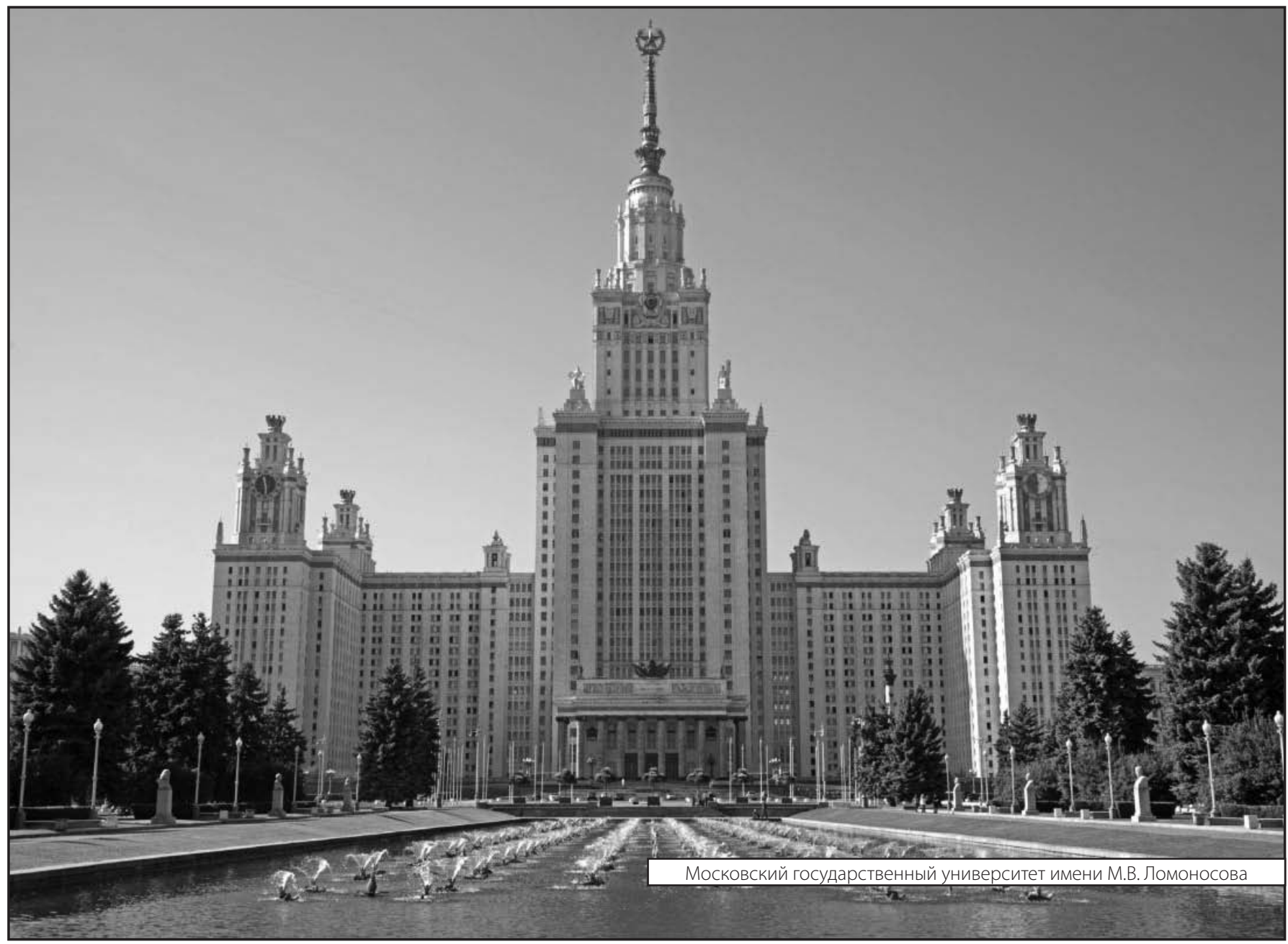

